\title{
The impact of bird herbivory on macrophytes and the resilience of the clear-water state in shallow lakes: a model study
}

\author{
Cassandra van Altena - Elisabeth S. Bakker • \\ Jan J. Kuiper - Wolf M. Mooij
}

Received: 16 November 2015/Revised: 10 April 2016/ Accepted: 13 April 2016/Published online: 14 May 2016

(C) The Author(s) 2016. This article is published with open access at Springerlink.com

\begin{abstract}
Shallow lakes have the potential to switch between two alternative stable states: a clear macrophyte-dominated and a turbid phytoplankton-dominated state. Observational and experimental studies show that in some lakes herbivory by birds may severely decrease macrophyte biomass, while in other lakes, the removed biomass by herbivory is compensated by regrowth. These contradictory outcomes might arise because of interplay between top-down control by bird herbivory and bottom-up effects by nutrient loading on macrophytes. Here, we use the ecosystem model PCLake to study top-down and
\end{abstract}

Handling editor: Alex Elliott

Electronic supplementary material The online version of this article (doi:10.1007/s10750-016-2779-6) contains supplementary material, which is available to authorized users.

C. van Altena

Biometris, Wageningen University, P.O. Box 16, 6700 AC Wageningen, The Netherlands

E. S. Bakker · J. J. Kuiper · W. M. Mooij ( $\square)$ Department of Aquatic Ecology, Netherlands Institute of Ecology (NIOO-KNAW), P.O. Box 50, 6700 AB Wageningen, The Netherlands e-mail: w.mooij@nioo.knaw.nl

\section{J. J. Kuiper · W. M. Mooij}

Aquatic Ecology and Water Quality Management Group, Department of Environmental Sciences, Wageningen University, P.O. Box 47, 6700 AA Wageningen,

The Netherlands bottom-up control of macrophytes by coots and nutrient loading. Our model predicted that (1) herbivory by birds lowers the critical nutrient loading at which the regime shift occurs; (2) bird impact on macrophyte biomass through herbivory increases with nutrient loading; and (3) improved food quality enhances the impact of birds on macrophytes, thus decreasing the resilience of the clear-water state even further. The fact that bird herbivory can have a large impact on macrophyte biomass and can facilitate a regime shift implies that the presence of waterfowl should be taken into account in the estimation of critical nutrient loadings to be used in water quality management.

Keywords Top-down versus bottom-up control . Alternative stable states · Ecosystem model · Grazing · Eutrophication · Water quality management

\section{Introduction}

Shallow lakes have the potential to switch between two alternative stable states: a clear macrophytedominated and a turbid phytoplankton-dominated state (Jeppesen et al., 1990; Scheffer, 1990; Carpenter, 2003). This switch can occur in response to gradual changes in external factors, such as nutrient loading, hydraulic loading, or temperature rise (Mooij et al., 2009), or in response to abrupt changes in one of the 
components of the aquatic food web through biomanipulation (Jeppesen et al., 1990; Meijer et al., 1999; Mehner et al., 2002). The clear-water state is often preferred not only by water quality managers because of the associated biodiversity but also for the intake of drinking water and recreational purposes (swimming and boating). Macrophytes play an important role in the resilience of the clear-water state (Carpenter \& Lodge, 1986; Scheffer et al., 1993), because they stabilize this state in multiple ways. For example, they reduce resedimentation of particles from the sediment of the lake (e.g. Horppila \& Nurminen, 2003). Also, they prevent phytoplankton growth by taking up available nutrients (e.g. van Donk \& van de Bund, 2002) and provide shelter for zooplankton (e.g. Shapiro, 1990). Because zooplankton are key grazers of phytoplankton and zooplankton abundance can be severely depleted by fish in the absence of shelter, macrophyte shelter for zooplankton supports the clearwater state in lakes.

Whereas it is widely acknowledged that bottom-up effects on submerged macrophytes through eutrophication play an important role in regime shifts in lakes, the importance of top-down control by herbivory on the macrophytes themselves remains unclear. Especially the effects of herbivory by waterbirds on submerged macrophytes is debated (Mitchell \& Perrow, 1998; Marklund et al., 2002). Grazing waterbirds, such as coots, swans, and ducks, can visit lakes in large numbers and feed on roots and shoots of submerged macrophytes. Some studies found that herbivory by birds decreased macrophyte biomass severely, even up to $100 \%$ (Sondergaard et al., 1996; Hilt, 2006; Wood et al., 2012; Bakker \& Nolet, 2014), while others found that the removed biomass is compensated by macrophyte regrowth (Mitchell \& Wass, 1996; Perrow et al., 1997; Hansson et al., 2010). This apparent contradiction may arise from the varying conditions under which these studies have been conducted, such as the macrophyte and the bird species under consideration, or the experimental set-up (Perrow et al., 1997; Bakker et al., 2013). A recent meta-analysis of all available field studies demonstrated that the impact of herbivory by birds on aquatic plants increases with bird biomass density, offering the first proof that birds systematically reduce macrophyte biomass when present at sufficient densities (Wood et al., 2012). Thus, differences in bird density could possibly explain the differences in experimental outcomes.
However, another explanation for the contradictions in experimental outcomes could be that bottomup effects through nutrient addition acts in concert with the top-down control on macrophytes by birds. It has been hypothesized that the impact of grazing birds on macrophytes varies with the nutrient status of the lake (Perrow et al., 1997; Weisner et al., 1997; Hansson et al., 2010; Bakker \& Nolet, 2014). Possible mechanisms for this could be that under eutrophic conditions plants have a higher nutrient content relative to their carbon content, making them more preferred food (Bakker \& Nolet, 2014), and that plants have less tolerance to grazing due to increased periphyton growth on the macrophytes (Weisner et al., 1997; Hilt, 2006; Hidding et al., 2010). These mechanisms could lead to a higher impact of herbivory by birds under more eutrophic but still transparent conditions. Enhanced consumption of macrophytes with increased plant quality would in particular apply to omnivorous waterfowl such as coot and dabbling and diving ducks. Other waterfowl species, in particular species of swans, geese, and some ducks are almost exclusively herbivorous and so their preference for macrophytes cannot increase (it is already $\sim 100 \%$ ) with macrophyte nutrient concentrations.

Another open question is whether the impact of herbivory by waterbirds is limited to a reduction of the standing crop of macrophytes or, alternatively, could eventually lead to a regime shift to the turbid state in lakes (van Donk \& Otte, 1996; Janse et al., 1998; Rip et al., 2006; Hansson et al., 2010). Herbivory induced regime shifts can be understood from the key role macrophytes play in stabilizing the clear state. If the impact of bird herbivory indeed increases under eutrophying conditions, then the largest impact would be close to the tipping point. Thus, in this already vulnerable phase, the resilience of the clear-water phase is decreased even further. However, there are currently no data available to test this hypothesis and therefore we used a modelling approach. A first attempt in this direction was made by Janse et al., (1998), who demonstrated with the ecosystem model PCLake that coot herbivory could indeed have caused the disappearance of macrophytes from restored Lake Zwemlust (The Netherlands) (van Donk \& Otte, 1996), leading to a shift to the turbid state.

Here, we go one step further by investigating the impact of herbivory on macrophyte biomass and the resilience of the clear-water state along a gradient of 
nutrient loadings. More specifically, we (1) calculate the effect of bird herbivory on the critical nutrient loading (CNL) at which the shift from clear to turbid water occurs (sensu Janse et al., 2010); (2) determine how the impact of bird herbivory on macrophyte biomass changes along a nutrient gradient; and (3) investigate how food quality could affect bird impact on macrophytes. We hypothesize that bird herbivory decreases the CNL by decreasing macrophyte biomass, and that the impact of bird herbivory will increase with nutrient loading because of improved quality of the macrophytes as food.

\section{Methods}

PCLake is a dynamic model based on differential equations that calculates the carbon (for historical reasons expressed as dry weight) and nutrient flows (primarily phosphorus and nitrogen) between the food web compartments in a shallow lake ecosystem (Janse $\&$ van Liere, 1995). Both the water column and the top layer of the sediment are included in the model. Trophic groups in the water column comprise three groups of phytoplankton (cyanobacteria, diatoms, and green algae), planktivorous/benthivorous fish, and piscivorous fish. The sediment layer includes settled phytoplankton and zoobenthos. Both water column and sediment layer contain pools for inorganic nutrients and detritus. We use the default set-up of PCLake where submerged macrophytes are modelled as one functional group, with a separately modelled shoot and root part (Janse, 2005). Macrophyte growth depends on water light conditions, temperature and available nutrients in both the water column and the sediment layer. It is assumed that the growing season starts when a critical water temperature is reached $\left(9^{\circ} \mathrm{C}\right)$, which happens in mid-April, using the long-term averaged seasonal water temperature of Dutch lakes. The growing season ends half September onwards, when part of the above-ground biomass is allocated to the below ground biomass and the mortality of the plants is raised such that $30 \%$ of the original biomass survivesthe overwintering parts (we listed the growth equations of the macrophytes in Online Appendix 1).

The model is known to show regime shifts between a clear, macrophyte-dominated state and a turbid, phytoplankton-dominated state when the nutrient loading is either increased (eutrophication) or decreased (re-oligotrophication) (Janse, 1997). The critical nutrient loading (hereafter referred to as CNL) at which the shift from the clear-water state to the turbid-water state occurs is higher than the CNL at which the reverse shift occurs. Thus, the model shows hysteresis and alternative stable states for intermediate levels of nutrient loading. In this study, we concentrate on the higher one of the two critical nutrient loadings, that is the CNL during eutrophication.

Herbivorous birds are modelled in PCLake as an external factor that reduces macrophyte biomass, following the approach of Janse et al. (1998). For a summary of all equations and parameters related to bird herbivory and macrophytes in PCLake, see Online Appendix 1. PCLake as whole is described in great detail in Janse (2005) (online available at http://edepot. wur.nl/121663). Throughout this manuscript, we focus on the resilience of the clear-water state. Here we use the term resilience within its ecological definition (as a basin of attraction sensu Holling, 1973) and not in its engineering definition (as a return time to equilibrium). To test whether the clear-water state forms a basin of attraction, we initialize the model in the clear-water state and check whether this state is maintained during the simulation, or alternatively, whether the system moves away from the clear-water state towards the turbid-water state. We define the CNL as the lowest nutrient loading where the clear-water state loses its resilience. The bi-stability of PCLake is studied in detail by Kuiper et al. (2015) in conjunction with food web theory and the positive feedbacks that maintains these alternative stable states.

Coots (Fulica atra Linnaeus, 1758) are taken as a model species, being common omnivorous waterbirds with a large share of plant material in their diet (e.g. Perrow et al., 1997; Wood et al., 2012). The amount of macrophyte biomass that is grazed by coots, $G$ (g dry weight $\mathrm{m}^{-2} \mathrm{~d}^{-1}$ ), is modelled with a Holling type II functional response as

$G=q \cdot V /\left(h_{d}+V\right) \cdot b / 10000 \cdot g$,

with $V$ the macrophyte biomass (g dry weight $\mathrm{m}^{-2}$ ), $q$ the preference of birds for macrophytes (dimensionless), $h_{d}$ the half-saturation constant (g dry weight $\mathrm{m}^{-2}$ ), $b$ the number of coots per ha (a parameter, divided by 10,000 because PClake uses $\mathrm{m}^{2}$ as the unit for surface), and $g$ the amount of macrophytes grazed per coot ( $g$ dry weight $\operatorname{coot}^{-1} \mathrm{~d}^{-1}$ ). We used the standard parameterization of PCLake $\left(h_{d}=5 \mathrm{~g}\right.$ dry 
weight $\mathrm{m}^{-2}$ and $g=45 \mathrm{~g}$ dry weight $\operatorname{coot}^{-1} \mathrm{~d}^{-1}$ ) (Janse et al., 1998). The intake rate of coots is based on van Donk \& Otte (1996) and Verhoeven (1980). Macrophyte biomass that is ingested but not assimilated by the coots is returned to the water compartment as detritus and freely available nutrients, while the fraction that is assimilated is lost from the system. The assimilation efficiency is kept the default value of 0.5 , while the fraction dissolved nutrients of the egested material is 0.25 (Janse, 2005).

To investigate the role of food quality, we defined the preference of coots for macrophytes $q$ in two ways. First, we performed the analyses for $q=1$, thus ignoring the role of food quality. Second, we let $q$ depend on the carbon-to-phosphorus ratio ( $\mathrm{C}: \mathrm{P}$ ratio) of the macrophytes, where low $\mathrm{C}: \mathrm{P}$ ratios are associated with high food quality and high $\mathrm{C}: \mathrm{P}$ ratios with low food quality. If this macrophyte $\mathrm{C}: \mathrm{P}$ ratio was lower than a reference value (see below), coots were allowed to eat up till $20 \%$ more macrophyte biomass than what they would eat when food quality was not taken into account (i.e. when $q=1$ ). If the $\mathrm{C}$ : $\mathrm{P}$ ratio was higher than the reference value, coots were allowed to eat up till $20 \%$ less macrophyte biomass. As a reference value, we used for each coot density $b$ the mid-range of all possible macrophyte C:P ratios along the nutrient loading axis when food quality was ignored. This led to the following formula for $q$ when food quality is taken into account:

$q= \begin{cases}0.8 & \text { for } \frac{C P}{C P_{\text {ref }}}<0.8 \\ \frac{C P}{C P_{\text {ref }}} & \text { for } 0.8 \leq \frac{C P}{C P_{\text {ref }}} \leq 1.2 \\ 1.2 & \text { for } \frac{C P}{C P_{\text {ref }}}>1.2 .\end{cases}$

with $\mathrm{CP}$ the $\mathrm{C}: \mathrm{P}$ ratio of macrophytes at any particular time step, and $C P_{\text {ref }}$ the mid-range reference value. We thus assume that birds eat more (less) macrophytes when macrophyte $\mathrm{C}: \mathrm{P}$ ratio is lower (higher) than the reference C:P ratio. Moreover, we assume that this change in food intake is proportional to the relative difference between the actual macrophyte $\mathrm{C}: \mathrm{P}$ ratio and the reference $\mathrm{C}: \mathrm{P}$ ratio. Please note that in absence of empirical data to base our value of $20 \%$ on, our analysis of the impact of food quality should be interpreted in an explorative fashion rather than in a predictive fashion.
We performed a bifurcation analysis with phosphorus (P) loading as the bifurcation parameter, which we varied between 0.35 and $5 \mathrm{mg} \mathrm{P} \mathrm{m}^{-2} \mathrm{~d}^{-1}$. The nitrogen loading was consistently kept at 10 times the $\mathrm{P}$ loading to maintain phosphorus limitation. We did this for six different coot densities ( $b$ in Eq. 1): 0, 5 , $10,20,35$, and 50 coots per ha. In the bifurcation analysis, the model was run for 20 years (c.f. Janse et al., 2008), starting on the lower end of the phosphorus gradient in conditions that represented a clear-water state. Birds were entered in the system after 10 years and were assumed to be present each year between February 15th and October 15th. Thus, we allowed the birds to be present the entire spring and summer. Additional analysis showed that allowing the birds to be present in winter, that is, from October 15th to February 15th, resulted in some quantitative differences while the qualitative patterns remained the same (Online Appendix 2). In the 20th year of the simulation, summer averages of chlorophyll-a were measured to determine the impact of bird herbivory on CNL. At the same moment, summer averages of macrophyte biomass were measured to determine the impact of bird herbivory on macrophyte biomass. We expressed bird impact as the reduction of macrophyte biomass in scenarios where birds were present, relative to the macrophyte biomass in the scenarios where birds were absent. This measure of bird impact allowed us to compare our results to what was found in field studies (e.g. Hansson et al., 2010; Wood et al., 2012). Please note that PCLake is a deterministic model and therefore needs to be run for each setting only once. A one-at-the-time sensitivity analysis was performed for several key parameters to check the robustness of the results (see Online Appendix 3).

\section{Results}

The critical nutrient loading (CNL) during eutrophication was lower when coots were present, compared to the situation when coots were absent (Fig. 1). When coots were absent, the CNL was $3 \mathrm{mg} \mathrm{P} \mathrm{m}^{-2} \mathrm{~d}^{-1}$. At a density of 10 coots $\mathrm{ha}^{-1}$, CNL was reduced by $18 \%$ $\left(\mathrm{CNL}=2.3 \mathrm{mg} \mathrm{P} \mathrm{m}^{-2} \mathrm{~d}^{-1}\right)$ compared to the CNL when coots were absent; at a density of 35 coots ha ${ }^{-1}$, CNL was even reduced by $70 \%(\mathrm{CNL}=1 \mathrm{mg} \mathrm{P}$ $\mathrm{m}^{-2} \mathrm{~d}^{-1}$ ), whereas at 50 coots $\mathrm{ha}^{-1}$, there was no stable clear-water state. Thus, herbivory by coots 
Fig. 1 Effect of grazing coots on chlorophyll-a along a nutrient loading axis during eutrophication. At a density of 50 coots ha ${ }^{-1}$, the model predicts that the lake is in the turbid state for all loadings

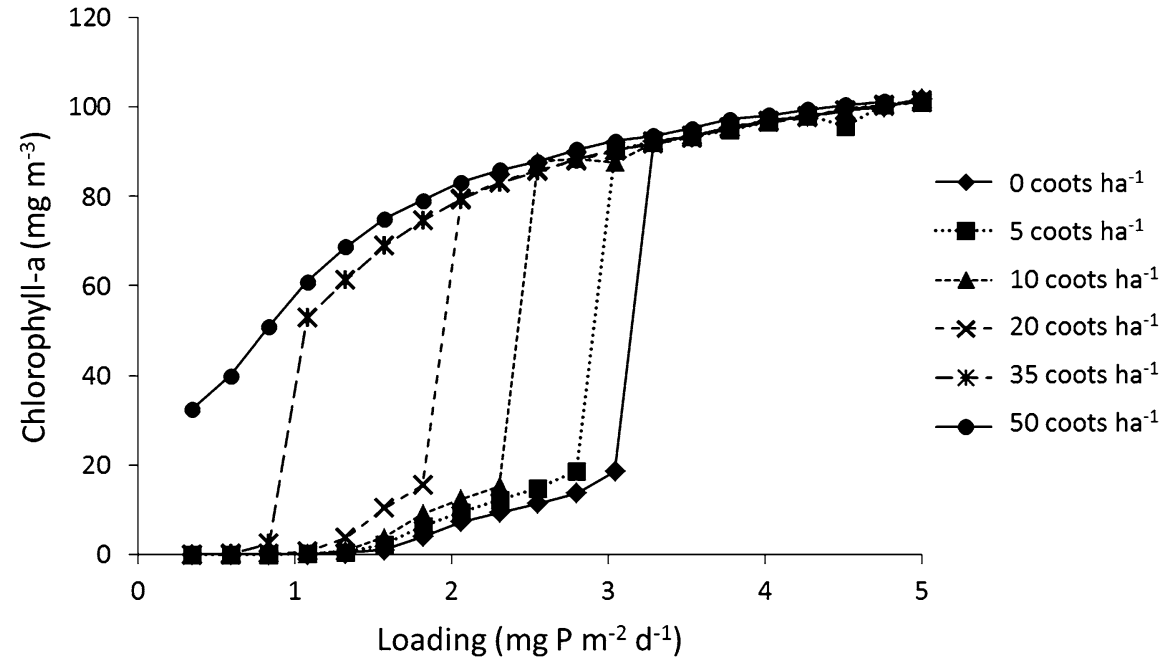

Fig. 2 Effect of grazing coots on macrophyte biomass along a nutrient loading axis during eutrophication. At a density of 50 coots ha ${ }^{-1}$, macrophytes were not present for any of the $\mathrm{P}$ loadings

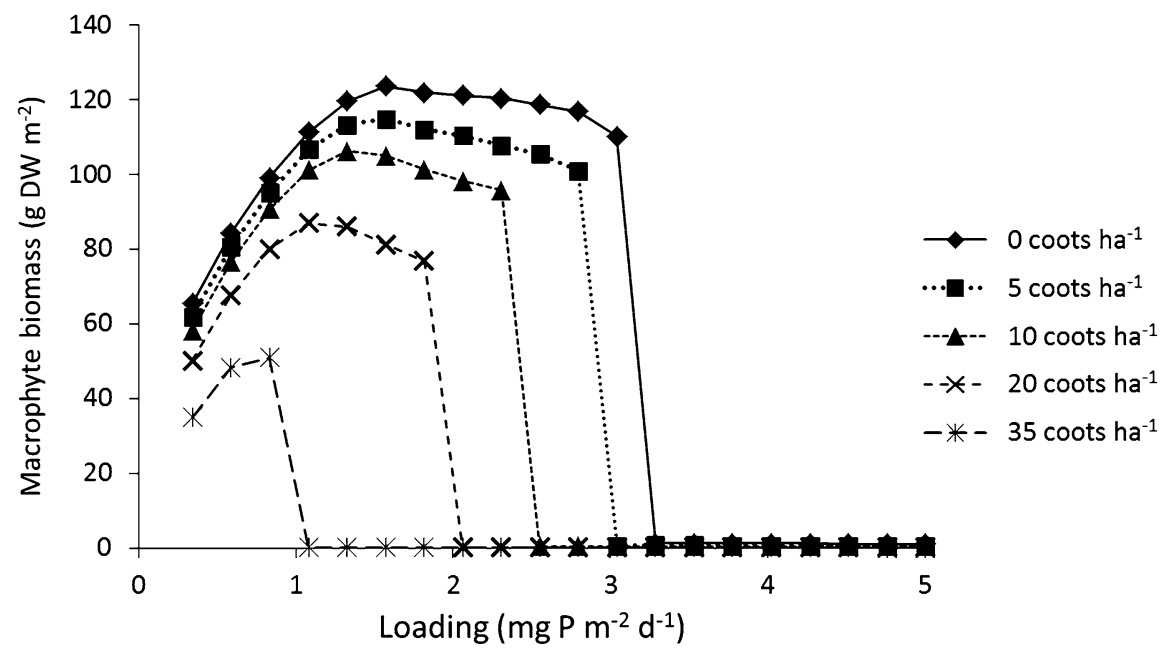

enhanced the transition of a clear to a turbid-water state and the higher the density of coots, the more the CNL was decreased.

Macrophyte biomass was lower when coots were present compared to the situation where coots were absent (Fig. 2). When coots were absent, macrophyte biomass first showed a steep increase with increasing P loading and then slowly decreased until macrophytes practically disappeared at the CNL where the switch to the turbid state occurred. This pattern was repeated when coots were present, but with increasingly lower macrophyte biomass at increasing bird density. This difference in biomass between the scenario with birds compared to the situation without birds becomes more prominent when the CNL is approached (Fig. 2). Because macrophytes completely disappear at lower CNL with increasing bird densities (see Fig. 1) the decrease in macrophytes at intermediate nutrient loadings is no longer present in the scenario with 35 coots $\mathrm{ha}^{-1}$. As macrophytes cannot coexist with 50 coots ha ${ }^{-1}$ (Fig. 1), we do not show the results for this scenario in this and the following analyses.

The impact of grazing coots, expressed as the percentage reduction in macrophyte biomass compared to the situation where coots were absent, was largest at very low nutrient loadings and near the CNL (Fig. 3). In between these extremes in nutrient loading, the impact of herbivory was smaller (Fig. 3). Bird impact also increased with coot density for all nutrient 
Fig. 3 The impact of birds, expressed as the percentage decrease in macrophyte biomass relative to macrophyte biomass in absence of birds, under different nutrient conditions during eutrophication. At a density of 50 coots $\mathrm{ha}^{-1}$, macrophytes were not present for any of the $\mathrm{P}$ loadings

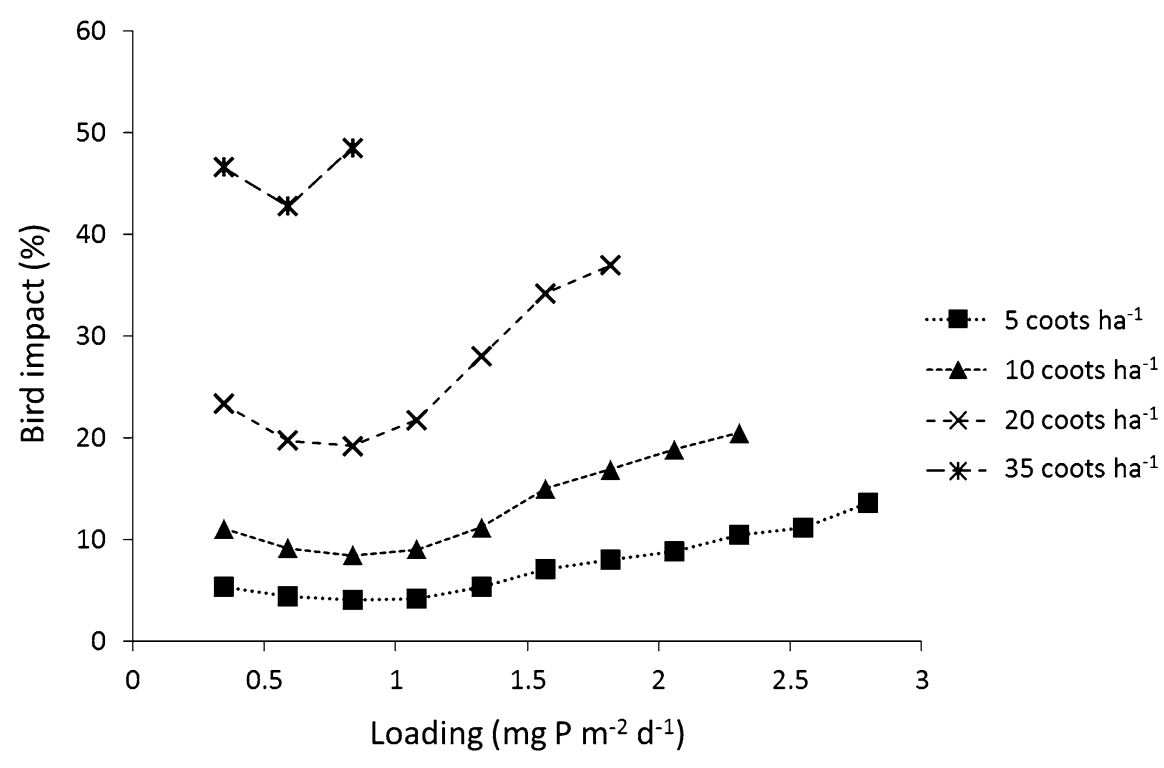

Fig. 4 C:P ratio of macrophytes decreases with increasing $\mathrm{P}$ loading and increasing coot density during eutrophication. At a density of 50 coots $\mathrm{ha}^{-1}$, macrophytes were not present for any of the $\mathrm{P}$ loadings

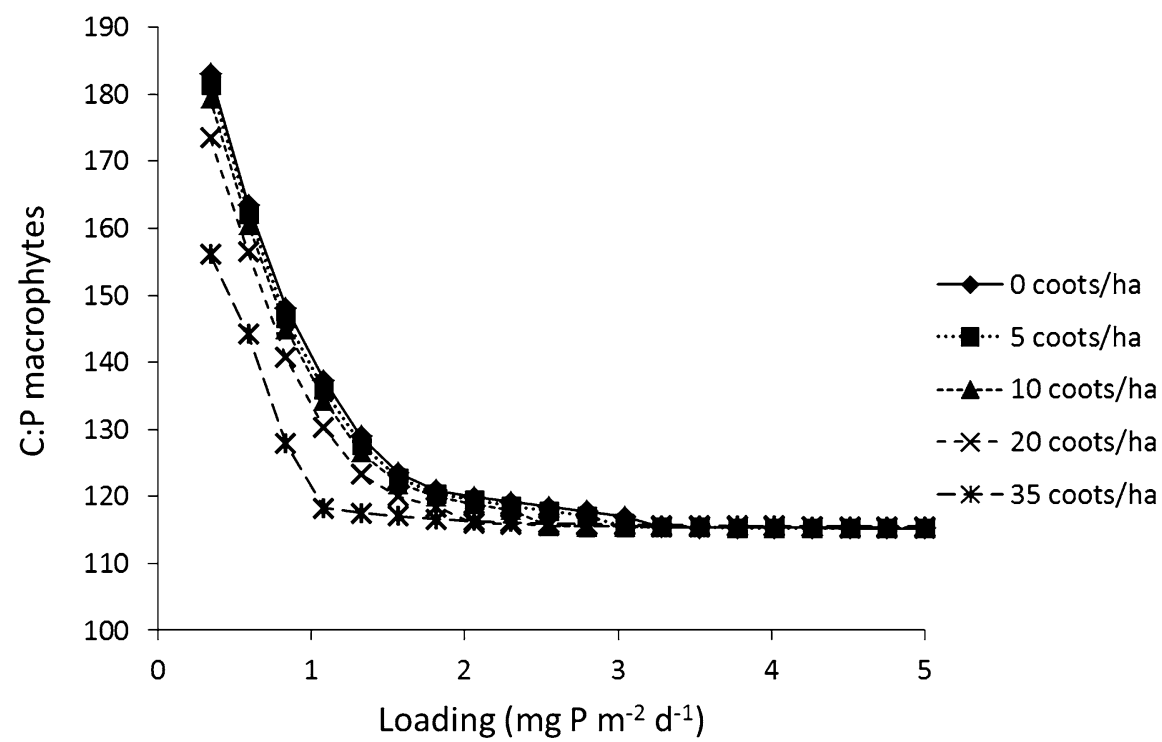

loadings: at a density of 10 coots ha ${ }^{-1}$, bird impact varied between $11 \%$ and $19 \%$, while at a density of 35 coots $\mathrm{ha}^{-1}$, bird impact varied between $43 \%$ and $48 \%$.

With the preference of coots for macrophytes $(q)$ set equal to one, the quality of macrophytes as food (measured as the C:P ratio) increased with increasing $\mathrm{P}$ loading (i.e. macrophyte $\mathrm{C}: \mathrm{P}$ ratio decreased, Fig. 4). For the reference value $C P_{\text {ref }}$ in Eq. 2, we took the mid-range of macrophyte $C: P$ ratios along the $\mathrm{P}$ loading axis $\left(0.35-5 \mathrm{mg} \mathrm{P} \mathrm{m} \mathrm{m}^{-2} \mathrm{~d}^{-1}\right)$. But because the macrophyte $\mathrm{C}: \mathrm{P}$ ratio decreased with increasing coot density as well, $C P_{\text {ref }}$ was defined for each coot density separately. For example, $C P_{\text {ref }}$ for a density of $5,10,20$, and 35 coots ha ${ }^{-1}$ was equal to 148,147 , 144 , and 135 , respectively.

When the analyses were performed with coot preference for macrophytes dependent on macrophyte $\mathrm{C}: \mathrm{P}$ ratio ( $q$ defined as in Eq. 2 ), the model predicted similar patterns for CNL (not shown), macrophyte biomass (not shown), and bird impact (Fig. 5) as in the situation where food quality was not taken into account $(q=1)$, but all effects were enhanced. 
Overall, coots grazed more biomass when their grazing rate was dependent on food quality, which resulted in an even lower CNL compared to the situation when food quality was not taken into account (not shown). At very low P loadings, bird impact was quite similar, especially for the lower coot densities (Fig. 5). With increasing $\mathrm{P}$ loadings the increase in bird impact as a result of improved food quality became more prominent until the CNL was reached.

\section{Discussion}

Many field studies and field experiments have been performed to determine the effects of birds on macrophyte biomass. Whereas it has been shown that birds significantly reduce macrophyte biomass at increasing bird biomass densities (Wood et al., 2012), the diversity in experimental set-ups masks the role of environmental factors, such as nutrient loading. Furthermore, it remains unclear whether the impact of birds on macrophyte biomass can induce a regime shift. Here, we used an established ecosystem model, PCLake, to test in a standardized way for different nutrient loadings what the impact of birds is on macrophyte biomass, and whether birds could induce a regime shift from a clear- to a turbid-water state. Our model predicted that: (1) bird herbivory lowers the critical nutrient loading at which the regime shift occurs, implying that at intermediate nutrient loadings birds can trigger a regime shift, (2) bird impact on macrophyte biomass through herbivory increases with nutrient status, and (3) improved food quality can enhance the impact of birds on macrophytes and thereby decrease the resilience of the clearwater state even further.

Previous studies have shown that grazing coots could be responsible for the decreasing resilience of the clear-water state in Lake Zwemlust, where at a density of more than 20 coots/ha and a nutrient loading of $2.4 \mathrm{~g} \mathrm{P} \mathrm{m}^{-2} \mathrm{~d}^{-1}$ (van Donk et al., 1993), the macrophytes eventually disappeared (van Donk \& Otte, 1996; Janse et al., 1998), which would also be predicted by our model. By means of the modelling study presented here, we can now generalize this finding for a range of bird densities and nutrient loadings. The range of chosen bird densities during summer that we used in our study (5-50 coots ha ${ }^{-1}$ ) encompasses densities as reported from field observations (Lauridsen et al., 1993; Sondergaard et al., 1996; Hilt, 2006). When bird herbivory was added at such densities to the food web, the critical nutrient loading (CNL) during eutrophication was lower than the CNL in the situation where birds were absent. This was true for all bird densities, but the reduction in the CNL became most prominent with increased bird densities. This result fits well with the results of Wood et al. (2012), who found that macrophyte reduction increases with increasing bird biomass density. It might be that in the field, the reduction in CNL is even larger than predicted by PCLake, as grazing birds can have further negative effects on the clear-water state via changes in nutrient cycling. For example, they could add allochthonous nutrients through their
Fig. 5 Bird impact when food quality is taken into account ( $q$ defined as in Eq. 2, black lines) during eutrophication. Bird impact without food quality $(q=1$, grey lines) is shown for comparison. At a density of 50 coots ha ${ }^{-1}$, macrophytes were not present for any of the $\mathrm{P}$ loadings

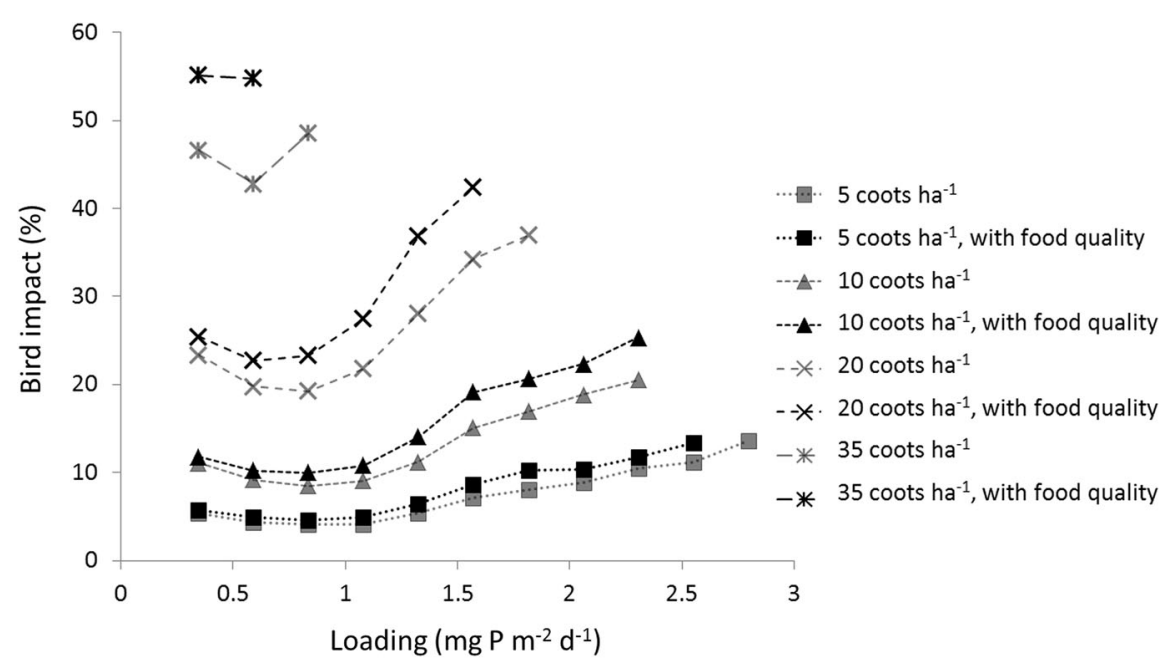


droppings, thereby contributing to eutrophication directly (Hahn et al., 2008; Chaichana et al., 2010). Another mechanism by which the impact of coots could be larger than predicted by PCLake is nonconsumptive destruction of macrophytes while foraging on invertebrates (Paillisson \& Marion, 2001).

In our model study, we saw that bird impact was highest near the critical nutrient loading (see Fig. 3), that is at the point where the resilience of the clearwater state breaks down (the clear-water state ceases to be a basin of attraction). Therefore, herbivory by birds has a synergistic effect with mechanisms that erode the resilience of the clear-water state during eutrophication, in particular shading by phytoplankton and periphyton in the case of freshwater lakes (Weisner et al., 1997; Hilt, 2006; Hidding et al., 2010). For very low nutrient loadings, however, bird impact decreased with increasing nutrient loading. This antagonistic effect is most likely caused by the low macrophyte biomass at very low nutrient loadings making the amount of macrophyte biomass that is grazed relatively large compared to the available biomass.

The measure we chose for bird impact, i.e. the relative change of macrophyte biomass compared to the situation without birds, has been used in many field studies with exclosure experiments (e.g. Perrow et al., 1997; Hilt, 2006; Hidding et al., 2010). The outcomes of these experiments were extremely variable, with bird impact ranging from zero or a few percent difference to $100 \%$ difference (i.e. complete removal; see references in Hansson et al., 2010; Wood et al., 2012). This is probably due to the highly variable experimental set-ups with different bird densities, different lake conditions, and different bird species. Our analyses showed that such a wide range in bird impact $(4.1-55 \%$ or even $100 \%$ if we include the herbivory induced turbid state with no macrophytes) is indeed a plausible outcome when we take nutrient status of the lake, bird density, and the effects of food quality on grazing rate into account. When comparing our data with these from field studies where coots were the main grazers (6 studies in the Wood et al., 2012 meta-analysis), we modelled coot densities representing 4-28 kg/ha biomass compared to $3-33 \mathrm{~kg} / \mathrm{ha}$ coot biomass found in the field studies, and $4 \%-55 \%$ impact on macrophyte biomass in our model versus $23 \%-75 \%$ impact in the field studies. This suggests that our model may even underestimate the impact of grazing by birds on macrophyte biomass and the resulting shift to the turbid state.

The hypothesis of Bakker \& Nolet (2014) states that macrophyte food quality would be higher in eutrophic lakes and that omnivorous birds would therefore increase the proportion of macrophytes in their diets. In support of this hypothesis, we showed that along with $\mathrm{P}$ loading macrophyte C:P ratio decreases and bird impact increases. But, although somewhat less prominent, the increase in bird impact with increasing nutrient load was also visible when we did not take food quality into account. Thus, an increase in food quality is probably not the only cause for an increase in bird impact with increased nutrient loading. It is important to note that because of the way in which we incorporated food quality (see Eq. 2), birds were not only allowed to eat more but also less of macrophytes compared to the reference situation in which food quality was not taken into account. In the scenarios that we analysed, however, birds always ate more macrophytes when food quality was taken into account. It is also interesting to see that macrophyte $\mathrm{C}: \mathrm{P}$ ratio decreases with increasing coot density as a result of nutrient recycling by grazing. This positive feedback between herbivores and plant quality is known in both aquatic and terrestrial systems (McNaughton et al., 1997; Sterner \& Elser, 2002; Krumins et al., 2015). Whereas our modelling results are supporting the hypothesis, it remains to be tested under field conditions. Macrophyte nutrient concentrations increase upon fertilization and are more preferred food under experimental conditions for omnivorous ducks and fish (Dorenbosch \& Bakker, 2011; Bakker \& Nolet, 2014), but in the field, the relation between environmental and macrophyte nutrient concentrations is less clear (e.g. Casey \& Downing, 1976). Furthermore, preference for macrophytes may vary over seasons and with life history events in the life cycle of the birds (e.g. Wood et al., 2014).

Using a model approach, we could investigate the effects of bird herbivory on macrophyte biomass and critical transitions in lakes in a systematic way. That is, nutrient loading and coot density were varied in a factorial design and all other aspects were kept constant. In our study, we focussed on the effects of nutrient loading and food quality on bird impact on macrophyte biomass. However, bird herbivory can influence regime shifts in other ways apart from 
grazing. For example, an effect regularly seen is that grazing birds alter macrophyte species composition, because they prefer certain macrophyte species over others (van Donk \& Otte 1996; Hidding et al., 2010; Gayet et al., 2011). Considering different macrophyte species may also be relevant because the exact effect of herbivory may depend on plant traits. Our sensitivity analysis (Online Appendix 3) indicated that the maximum growth rate of the macrophytes has a relatively large influence on the results.

Another logical extension of the model would be to include strictly herbivorous bird species such as mute swans to the model. This would be particularly interesting because it would add the contrast between purely herbivorous birds (for instance mute swans) and omnivorous birds (coots) to the model. Our winter analysis showed that also the timing of grazing is a factor that is worth further exploring (Online Appendix 2). Grazing during the winter appears to affect the growth potential during the start of the growing season, as it complicates the competition with phytoplankton for light and nutrients (Scheffer 2004, p. 280). Thereby winter grazing can have a considerable effect on the conditions of the lake in the summer. Making birds a dynamic factor in the model may also seem a logical extension but is not easy because most waterbirds spend part of their life cycle outside the lake.

The fact that bird herbivory can have a large impact on macrophyte biomass and can accelerate a regime shift implies that the presence of waterfowl should be taken into account in water quality management scenarios. Complex ecosystem models such as PCLake are frequently applied by lake managers as part of a system analysis to obtain insight in the functioning of their lake and to estimate the CNL. These considerable efforts in estimating the CNL pay off because the concept of CNL provides lake managers with a straightforward-dependent variable to steer upon, as the actual phosphorus loading can easily be compared with the CNL, and the concept is simple to communicate to stakeholders (Stillman et al., 2016). Our study shows that bird density is important to take into account to obtain the most accurate prediction of the CNL. Although we show that the CNL of a lake is negatively affected by grazing birds, controlling their abundance (see for instance discussion on management of mute swans (Wood et al., 2013; Gayet et al., 2014) would not bring a sustainable solution: the impact of birds is highest in the domain where the resilience of the clear- water state is already low because of high nutrient loading. While bird management may potentially be part of a set of management measures that can be applied to increase the resilience of the clear-water state, the vulnerability to regime change during eutrophication is primarily a function of the external nutrient loading (Scheffer et al., 1993). Nutrient input reductions should therefore form the basis of any management program aiming at safeguarding the clear-water state. Given the freedom of birds to move from one lake to another, when considering the impact of birds, regional (or even larger) scales are important besides local scales.

In summary, in this model study, we showed that bird herbivory can decrease macrophyte biomass in shallow lakes to such an extent that a regime shift from a clear-water state to a turbid-water state is initiated. If birds respond to improved food quality with increased grazing, then the probability of such a shift is even enhanced. Taking a model approach to study the effects of bird herbivory on macrophytes and the state of the lake reveals that birds should be taken into serious consideration by water quality managers who try to preserve or recover the clear-water state of the lake.

Acknowledgments CVA is funded by the Netherlands Organisation for Scientific Research (NWO Project No. 645.000.013). JJK is funded by the Netherlands Foundation for Applied Water Research (STOWA) Project No. 443237 and the Netherlands Environmental Assessment Agency (PBL). We thank Jan Janse for his help with running PCLake. We thank Jan Janse, Lia Hemerik, and Peter de Ruiter for their constructive comments on an earlier version of this manuscript. This is publication 6091 of the Netherlands Institute of Ecology (NIOO-KNAW).

Open Access This article is distributed under the terms of the Creative Commons Attribution 4.0 International License (http:// creativecommons.org/licenses/by/4.0/), which permits unrestricted use, distribution, and reproduction in any medium, provided you give appropriate credit to the original author(s) and the source, provide a link to the Creative Commons license, and indicate if changes were made.

\section{References}

Bakker, E. S. \& B. A. Nolet, 2014. Experimental evidence for enhanced top-down control of freshwater macrophytes with nutrient enrichment. Oecologia 176(3): 825-836.

Bakker, E. S., J. M. Sarneel, R. D. Gulati, Z. Liu \& E. van Donk, 2013. Restoring macrophyte diversity in shallow temperate 
lakes: biotic versus abiotic constraints. Hydrobiologia 710(1): 23-37.

Carpenter, S., 2003. Regime Shifts in Lake Ecosystems: Patterns and Variation. Ecology Institute, Oldendorf/Luhe.

Carpenter, S. R. \& D. M. Lodge, 1986. Effects of submersed macrophytes on ecosystem processes. Aquatic Botany 26(3-4): 341-370.

Casey, H. \& A. Downing, 1976. Levels of inorganic nutrients in Ranunculus penicillatus var. calcareus in relation to water chemistry. Aquatic Botany 2: 75-79.

Chaichana, R., R. Leah \& B. Moss, 2010. Birds as eutrophicating agents: a nutrient budget for a small lake in a protected area. Hydrobiologia 646(1): 111-121.

Dorenbosch, M. \& E. S. Bakker, 2011. Herbivory in omnivorous fishes: effect of plant secondary metabolites and prey stoichiometry. Freshwater Biology 56: 1783-1797.

Gayet, G., M. Guillemain, H. Fritz, F. Mesleard, C. Begnis, A. Costiou, G. Body, L. Curtet \& J. Broyer, 2011. Do mute swan (Cygnus olor) grazing, swan residence and fishpond nutrient availability interactively control macrophyte communities? Aquatic Botany 95(2): 110-116.

Gayet, G., M. Guillemain, P. Defos du Rau \& P. Grillas, 2014. Effects of mute swans on wetlands: a synthesis. Hydrobiologia 723: 195-204.

Hahn, S., S. Bauer \& M. Klaassen, 2008. Quantification of allochthonous nutrient input into freshwater bodies by herbivorous waterbirds. Freshwater Biology 53(1): 181-193.

Hansson, L.-A., A. Nicolle, C. Bronmark, A. Hargeby, A. Lindstrom \& G. Andersson, 2010. Waterfowl, macrophytes, and the clear water state of shallow lakes. Hydrobiologia 646(1): 101-109.

Hidding, B., E. S. Bakker, F. Keuper, T. de Boer, P. P. de Vries \& B. A. Nolet, 2010. Differences in tolerance of pondweeds and charophytes to vertebrate herbivores in a shallow Baltic estuary. Aquatic Botany 93(2): 123-128.

Hilt, S., 2006. Recovery of Potamogeton pectinatus L. stands in a shallow eutrophic lake under extreme grazing pressure. Hydrobiologia 570: 95-99.

Holling, C. S., 1973. Resilience and stability of ecological systems. Annual Review of Ecology and Systematics 4: 1-23.

Horppila, J. \& L. Nurminen, 2003. Effects of submerged macrophytes on sediment resuspension and internal phosphorus loading in Lake Hiidenvesi (southern Finland). Water Research 37(18): 4468-4474.

Janse, J. H., 1997. A model of nutrient dynamics in shallow lakes in relation to multiple stable states. Hydrobiologia 342: 1-8.

Janse, J. H., 2005. Model studies on the eutrophication of shallow lakes and ditches. Wageningen University.

Janse, J. H. \& L. van Liere, 1995. A modelling tool for the evaluation of lake restoration scenarios. Water Science and Technology 31(8): 371-374.

Janse, J. H., E. Van Donk \& T. Aldenberg, 1998. A model study on the stability of the macrophyte-dominated state as affected by biological factors. Water Research 32(9): 2696-2706.

Janse, J. H., L. N. De Senerpont Domis, M. Scheffer, L. Lijklema, M. Klinge, W. M. Mooij \& L. van Liere, 2008. Critical phosphorus loading of different types of shallow lakes and the consequences for management estimated with the ecosystem model PCLake. Limnologica 38(3-4): 203-219.

Janse, J. H., M. Scheffer, L. Lijklema, L. Van Liere, J. S. Sloot \& W. M. Mooij, 2010. Estimating the critical phosphorus loading of shallow lakes with the ecosystem model PCLake: sensitivity, calibration and uncertainty. Ecological Modelling 221(4): 654-665.

Jeppesen, E., J. P. Jensen, P. Kristensen, M. Sondergaard, E. Mortensen, O. Sortkjaer \& K. Olrik, 1990. Fish manipulation as a lake restoration too in shallow, eutrophic temperate lakes 2. Threshold levels, long-term stability and conclusions. Hydrobiologia 200: 219-227.

Krumins, J. A., V. Krumins, E. Forgoston, L. Billings \& W. H. van der Putten, 2015. Herbivory and stoichiometric feedbacks to primary production. Plos One 10(6): e0129775.

Kuiper, J. J., C. van Altena, P. C. de Ruiter, L. P. A. van Gerven, J. H. Janse \& W. M. Mooij, 2015. Food-web stability signals critical transitions in temperate shallow lakes. Nature communications 6: 7727.

Lauridsen, T. L., E. Jeppesen \& F. O. Andersen, 1993. Colonization of submerged macrophytes in shallow fish manipulated lake Vaeng - impact of sediment composition and waterfowl grazing. Aquatic Botany 46(1): 1-15.

Marklund, O., H. Sandsten, L. A. Hansson \& I. Blindow, 2002. Effects of waterfowl and fish on submerged vegetation and macroinvertebrates. Freshwater Biology 47(11): 2049-2059.

McNaughton, S. J., F. F. Banyikwa \& M. M. McNaughton, 1997. Promotion of the cycling of diet-enhancing nutrients by African grazers. Science 278(5344): 1798-1800.

Mehner, T., J. Benndorf, P. Kasprzak \& R. Koschel, 2002. Biomanipulation of lake ecosystems: successful applications and expanding complexity in the underlying science. Freshwater Biology 47(12): 2453-2465.

Meijer, M. L., I. de Boois, M. Scheffer, R. Portielje \& H. Hosper, 1999. Biomanipulation in shallow lakes in The Netherlands: an evaluation of 18 case studies. Hydrobiologia 408: 13-30.

Mitchell, S. F. \& R. T. Wass, 1996. Grazing by black swans (Cygnus atratus Latham), physical factors, and the growth and loss of aquatic vegetation in a shallow lake. Aquatic Botany 55(3): 205-215.

Mitchell, S. F. \& M. R. Perrow, 1998. Interactions between grazing birds and macrophytes. In Jeppesen, E., M. Sondergaard, M. Sondergaard \& K. Christoffersen (eds), The structuring role of submerged macrophytes in lakes. Springer, New York: 175-196.

Mooij, W. M., L. N. D. Domis \& J. H. Janse, 2009. Linking species- and ecosystem-level impacts of climate change in lakes with a complex and a minimal model. Ecological Modelling 220(21): 3011-3020.

Paillisson, J. M. \& L. Marion, 2001. Interaction between coot (Fulica atra) and waterlily (Nymphaea alba) in a lake: the indirect impact of foraging. Aquatic Botany 71(3): 209-216.

Perrow, M. R., J. H. Schutten, J. R. Howes, T. Holzer, F. J. Madgwick \& A. J. D. Jowitt, 1997. Interactions between coot (Fulica atra) and submerged macrophytes: the role of birds in the restoration process. Hydrobiologia 342: 241-255. 
Rip, W. J., N. Rawee \& A. de Jong, 2006. Alternation between clear, high-vegetation and turbid, low-vegetation states in a shallow lake: the role of birds. Aquatic Botany 85(3): 184-190.

Scheffer, M., 1990. Multiplicity of stable states in fresh-water systems. Hydrobiologia 200: 475-486.

Scheffer, M., 2004. Ecology of Shallow Lakes. Springer, Netherlands.

Scheffer, M., S. H. Hosper, M. L. Meijer, B. Moss \& E. Jeppesen, 1993. Alternative equilibria in shallow lakes. Trends in Ecology \& Evolution 8(8): 275-279.

Shapiro, J., 1990. Biomanipulation: the next phase - making it stable. Hydrobiologia 200: 13-27.

Sondergaard, M., L. Bruun, T. Lauridsen, E. Jeppesen \& T. V. Madsen, 1996. The impact of grazing waterfowl on submerged macrophytes: in situ experiments in a shallow eutrophic lake. Aquatic Botany 53(1-2): 73-84.

Sterner, R. \& J. Elser, 2002. Ecological Stoichiometry: The Biology of Elements from Molecules to Biosphere. Princeton University Press, Princeton, NJ.

Stillman, R. A., K. A. Wood \& J. D. Goss-Custard, 2016. Deriving simple predictions from complex models to support environmental decision-making. Ecological Modelling 326: 134-141.

van Donk, E. \& A. Otte, 1996. Effects of grazing by fish and waterfowl on the biomass and species composition of submerged macrophytes. Hydrobiologia 340(1-3): 285-290. van Donk, E. \& W. J. van de Bund, 2002. Impact of submerged macrophytes including charophytes on phyto- and zooplankton communities: allelopathy versus other mechanisms. Aquatic Botany 72(3-4): 261-274.

van Donk, E., R. D. Gulati, A. Ledema \& J. T. Meulemans, 1993. Macrophyte-related shifts in the nitrogen and phosphorus contents of the different trophic levels in a biomanipulated shallow lake. Hydrobiologia 251: 19-26.

Verhoeven, J. T. A., 1980. The ecology of Ruppia dominated communities in Western Europe. III. Aspects of production, consumption and decomposition. Aquatic Botany 8: 209-253.

Weisner, S. E. B., J. A. Strand \& H. Sandsten, 1997. Mechanisms regulating abundance of submerged vegetation in shallow eutrophic lakes. Oecologia 109(4): 592-599.

Wood, K. A., R. A. Stillman, R. T. Clarke, F. Daunt \& M. T. O'Hare, 2012. The impact of waterfowl herbivory on plant standing crop: a meta-analysis. Hydrobiologia 686(1): 157-167.

Wood, K. A., R. A. Stillman, F. Daunt \& M. T. O’Hare, 2013. Evaluating the effects of population management on a herbivore grazing conflict. Plos One 8: e56287.

Wood, K. A., R. A. Stillman, F. Daunt \& M. T. O’Hare, 2014. Can sacrificial feeding areas protect aquatic plants from herbivore grazing? Using behavioural ecology to inform wildlife management. Plos One 9(7): e104034. 